\title{
Do abortamento criminoso em São Paulo
}

Trabalho apresentado á Sociedade de Medicina Legal e Criminología de São Daulo pelo doutorando Caetano Zamittí Mammana.

\begin{abstract}
A PRATICA do abortamento criminoso, não obstante as mais severas sançõos penaes, tem-se diffundido entre os differentes povos e hoje, como uma necessidade imposta pela civilisação, se tornou uma verdadeira praga social. $\mathrm{Na}$ época actual os differentes estudiosos desse assumpto, estão de accordo em reconhecer-lhe uma marcha verdadeiramente assustadora.

No nosso internato na Assistencia Policial tivemos occasião de observar diversas mulheres apresentando grandes hemorrhagias uterinas porst-aborto provocado. Ficou nosso espirito fortemente impressionado com a frequencia de casos de tal ordem, de modo que assentámos, desde então, que o assumpto da nossa these de doutorando seria sobre um ponto que se referisse ao "Abortamento criminoso"
\end{abstract}

Não é -absolutamente um thema novo, nem mesmo pretendemos enriquecel-o com contribuições pessoaes, mas nos limitaremos a descrever os meios mais commumente empregados entre nós, baseados nos exames feitos no Gabinete Medico-Legal nestes ultimos 13 annọ, e investigações por nós emprehendidas.

O abortamento criminoso em São Paulo está em voga e impressiona sobre maneira a frequencia com que se succedem os casos. Se recorremos ás estatisticas por mais bem organisadas que elles sejam, vemos que seus dados não exprimem a verdade completa, pois é certo que uma porcentagem elevadissima ou melhor a maioria absoluta, escapa, forçosamente, ao conhecimento official.

E isso por diversas razōes. Para confirmarmos o que acabamos de dizer, basta citar que no espaço de tempo decorrido de Janeiro de 1914 a fins de Julho do corrente anno constam no Gabinete MedicoLegal 37 exames, sendo, um correspondente a este ultimo mez. No emtanto, durante esse mesmo mez uma parteira de um dos bairros proximos do centro, tida como honestissima, provocou 176 aborta- 
mentos sem ter tido nenhum caso que lhe desse cuidados; outra parteira residente em bairro differente, provocou 40 abortamentos dos quaes um com grande hemorrhagia uterina, sendo encessaria a remoção da paciente para um hospital. Grande foi o numero de abortamentos provocados criminosamente por outras parteiras nesse mesmo mez. Se fossemos calcular numa cifra redonda creio que passariamos das casas dos 300, e no emtanto no Gabinete Medico-Legal só consta um exame.

Para o numero diminuto dos casos de abortamento criminoso que chegam ao conhecimento da policia, ha abertura de inquerito, e, este sempre ou quasi sempre termina sendo archivado por falta de provas.

Dos factos consumados, sómente uma parte infinitesimal é denunciada e mesmo assim por circumstancias especiaes, entre as quaes as mais communs são:

$1 .^{\circ}$ - Complicações consequentes a manobras abortivas;

$20^{\circ}$ - Morte da mulher;

$3^{\circ}$ - Quando a mulher é recolhida numa clinica ou hospital;

$4 .^{\circ}$ - Por acaso quando se procede uma pericia num caso de violencia carnal;

5. - Quando sejam encontradas as partes expulsas.

1. - Complicaçōes consequentes a manobras abortivas: Em vista da perfeição da technica empregada na effectuação das manobras abortivas e de um modo especial pelos cuidados maiores tomados por quem os pratica essas complicações são relativamente raras e as denuncias são em numero diminuto e assim mesmo isso se dá quando o caso é muito grave e a vida da paciente corre perigo.

2. - Morte da mulher: Dentre as circumstancias citadas esta é a mais frequente. Nestes ultimos 13 annos tivemos em São Paulo 9 casos de morte em consequencia a manobras abortivas, sendo um na propria residencia da parteira.

3.' - Quando a mulher é recolbida numa clinica on hospital: Estes casos são rarissimos, porque quando uma mulher é removida, além do interesse proprio em guardar segredo, já recebeu todas as instrucçöes necessarias por parte da pessoa que provocou o abortamento ou dos membros da familia, de modo que se se proceder a um interrogatorio ellas com a maior naturalidade se limitam a dar respostas como estas: "levei um tombo", "cahi de uma escada" "levei um grande susto" "briguei com meu marido" etc.

$4^{\circ}$ - Por acaso quando se procede a umia pericia num caso de violencia carnal: Pode-se dar o caso, de, raparigas levadas ao Gabinete Medico-Legal com o fim de serem examinadas, sobre a integridade de seus orgãos genitaes numa suspeita de defloramento, e o perito notar signaes evidentes de abortamento.

Dentre as observações por nós colhidas no Gabinete Medico-Legal referimos a seguinte, que bem demonstra o que acabamos de dizer: 


\section{Obs. N. ${ }^{\circ} \quad$.}

M. C., branca, brasileira, solteira, com 21 annos de idade.

Num dos dias do mez de Março de 1921 compareceu ao Gabinete Medico-Legal, afim de ser examinada. Referiu que ha 6 mezes, mais ou menos, fôra seduzida por um individuo com o qual tivera varias relações sexuaes e que anteriormente ao seu defloramento, já não apresentava o corrimento menstrual, havia 4 mezes. Referiu mais que no dia 29-12-1920 eliminara um coagulo de sangue acompanhado de colicas uterinas.

Pelo exame meticuloso dos orgãos genitaes notaram os peritos, além dos signaes evidentes do defloramento, outros que indicavam ter havido um aborto, devendo o producto da concepçãó ter de accordo com as lesões observadas no collo do utero de 3 a 4 mezes.

5. - Quando sejam encontradas as partes expulsas: São os casos mais communs e os mais difficeis de se resolver, de modo que sempre ou quasi sempre permanecem no mysterio. Poucos são os casos deste genero que a Policia consegue desvendar. A titulo de exemplo citarei um interessante que se elucidou, graças ao resultado de uma pericia muito bem orientada.

No mez de Fevereiro de 1917, foram os peritos, medicos do nosso Gabinete Medico-Legal, incumbidos de ir á rua Lopes Chaves, afim de examinar uma mulher, A. A., com 30 annos de edade, branca, portugueza, casada, ahi residente. Suspeitava a autoridade policial que no dia 26-1-1917, ella abandonara o producto da concepção num terreno do"bairro das Perdizes. Passaram os peritos ao exame ordenado e investigações que julgavam necessarias, findas as quaes declararam:

Interrogada sobre o facto, A. A., affirmou ser essa imputação uma calumnia, fructo das inimizades com algumas vizinhas suas. Disse no emtanto soffrer de um mal antigo, consistindo no augmento paulatino do volume do ventre, que no fim de 10 e ás vezes 12 mezes attinge seu maximo. Nessa occasião, perde grande quantidade de sangue, perda que se prolonga por espaço de varios dias, e como consequencia o ventre baixa.

Decorrido algum tempo, de novo o ventre se avoluma seguindo o mal, a sua serena evolução. Disse mais, que durante esșa phase de augmento progressivo do volume do ventre, não apresenta o corrimento menstrual. O seu estado geral fica ligeiramente perturbado somente por occaião da phase final do processo, sentindo ás vezes no concluir do mesmo, ligeiras dôres no interior do ventre. Referiu ter 4 filhos, datando o ultimo parto ha 4 annos.

Informa que dessa época até o dia do exame, já por 3 vezes o seu mal tem a evolução completa. Dias antes do exame, isto é, aos 23-1-1917, após ligeiro máo-estar, perdeu grande quatidade de sangue, seguindo-se a esta perda, o abaixamento rapido da parede ventral, vindo então a terminar, mais uma vez o processo que então estava no seu auge. Disse que a perda sanguinea, muito abundante no 
dia referido, diminuiu nos 4 dias consecutivos, mantendo-se até a data do exame um corrimento que parece, segundo espressão por ella usada: aguadilba de sangue. Depois do exame, os peritos concluiram tratar-se de um caso e aborto recente, devendo o producto da concepção ser mais ou menos desenvolvido.

Uma vez estudadas as causas que, de modo geral determinam a denuncia, passaremos aos meios empregados entre nós para a provocação do abortamento.

\section{MEIOS ABORTIVOS EMPREGADOS FREQUENTEMENTE EM SÃO PAULO}

Seguindo a classificação adoptada pela maioria dos autores, dividiremos os meios abortivos em:

$10^{\circ}$ - Meios abortivos internos; ou chimicos ou bio-chimicos;

2. - Meios abortivos mechanicos ou physicos;

3. - Meios abortivos psychicos ou bio-dynamicos;

Entre nós se usa com muita frequencia a associação do primeiro ao segundo methodo e que denominaremos de:

$4 .^{\circ}$ - Meio abortivo mixto ou mechanico-chimico.

Deixando de lado o modo pelo qual se dá o abortamento, quer pela ingestão de uma determinada substancia, quer pela applicação deste ou aquelle meio, passaremos a enumerar quaes sejam entre nós os meios mais em voga, documentando-os do melhor modo possivel.

\section{MEIOS ABORTIVOS INTERNOS}

Entre as substancias mais usadas temos: Os saes de quinino (sulfato ou chlorhydrato), aguardente allemã, pilulas de taurina, decocto de differentes hervas, agua viennense, chá de canella com pinga, diversos preparados de ergotina, sulfato de strychnina, etc.

Saes de quinino: Os mais usados são o sulfato e o chlorhydrato, e o seu emprego raramente determina o abortamento. Possuimos diversas observações em que seu emprego deu resultados positivos e grande numero de casos em que para nada valeu. Citaremos dois casos interessantes:

Observação N.・ 1 :

M. G., com 27 annos, parda, brasileira, solteira.

A conselho de sua mãe, procurou a parteira M., afim de fazer abortar. Esta lhe administrou diversas capsulas de quinino. Voltando para sua residencia foi acommettida de fortes dôres abdominaes, graves perturbações geraes e veio a fallecer dias depois. A autopsia revelou que a morte se dera em consequencia a uma infecção decorrente de um aborto, sendo qu o fructo da concepção apresentado 
aos peritos tinha approximadamente 4 mezes e meio, e não apresentava bem como M. G. vestigio algum de qualquer manobra que tivesse por fim a sua eliminação do ventre materno.

Observação N ${ }^{\circ}$ 2:

M. T., com 35 annos, branca, viuva, brasileira.

Estando gravida, e como quizesse esconder o fructo de seus amores illicitos, procurou a parteira $\mathrm{Y}$ Esta lhe applicou por diversas vezes, uma sonda molle, sem obter os resultados desejados. Dirigiu-se então a uma Pharmacia proxima á sua residencia e pediu ao pharmaceutico para que lhe desse um bom remedio que a tirasse daquella situação. Este lhe preparou 6 capsulas de quinino, dizendo-lhe para que tomasse uma de duas em duas horas. M. T. não seguiu a indicação, mas tomou as seis capsulas de uma só vez. Momentos depois sentiu fortes dôres abdominaes, tonturas, zoadas nos ouvidos, etc., e abortou.

Aguiardente allemã e agua viennense: Estes drasticos são muito usados entre nós. Não ha mulher que, procurando provocar o aborto não tente em primeiro lugar com um destes purgantes. Hoje grande numero de pharmaceuticos, consultados por mulheres gravidas que querem abortar, preparam sem escrupulo, 40 a 60 grammas - verdadeira dose de cavallar - de aguardente allemã ou de agua viennense, accrescentando no momento da entrega: "Pode tomar sem medo, porque este remedio não falha!"

Casos desta ordem ha muitos. Certas mulheres costumam tomar ao mesmo tempo uma dose de aguardente allemã e em seguida algumas capsulas de quinino.

Observação $\mathrm{N}^{\circ} \cdot 3$ :

A. O. N., com 17 annos, solteira, branca, brasileira.

Affirma ter sido deflorada por um individuo seu conhecido, e que ha cerca de 3 mezes não apresenta seu fluxo menstrual. Refere que abortou após ter ingerido diversas capsulas de um sal de quinino e uma dose de aguardente allemã. Pelo exame da paciente, feito no Gabinete Medico-Legal, concluiu-se que ella esteve gravida e apresentava signaes evidentes de um aborto recente.

Pilulas de taurina: São muito usadas entre a gente do povo. Conhecemos diversos casos e entre elles citaremos o seguinte:

Observação N. ${ }^{\circ} 4$ :

$X$., com 25 annos, viuva, branca, brasileira.

Amante de um estudante de medicina, e estando gravida de dois mezes e meio, pediu a este qual seria o meio melhor que a salvaria daquella situação embaraçosa. Este, depois de ter consultado diversos livros e ter indagado com diversos pharmaceuticos sobre o medicamento que deveria empregar, escolheu a taurina. Comprou então 4 pilulas dessa substancia e as deu á amante para que as tomasse durante o dia com algum intervallo entre uma e outra. Horas depois de ter ingerrido a ultima, teve profusa hemorrhagia e abortou. 
Decoto de differentes hervas: E' muito empregado entre o povo que vive em contacto com curandeiros e espiritas.

Observação N. 5:

Rosalia G., com 38 annos, branca, viuva, franceza.

Luiz V., tendo conhecimento da morte de sua amante Rosalia, G. accusou a irmã desta, Sophia G., como autora. Segundo sua accusação, e cujas declarações constam no inquerito, esta lhe teria administrado o decoto de algumas hervas, por elle desconhecidas, com o fim de fazel-a abortar. Pela autopsia verificou-se que a causa-mortis fôra uma peritonite generalisada, tendo como ponto de partida uma infecção puerperal. As pesquizas toxicologicas feitas com o fim de se determinar a substancia empregada nada revelaram.

Chá de cannella com pinga: Entre o vulgo é tido como um optimo abortivo e por isso é muito empregado. Ao que parece, neste caso a substancia activa é o alcool.

Observação N. ${ }^{\circ}$ :

P. A. C., com 22 annos, branca, brasileira, casada.

Trata-se de uma mulher de constituição forte. Tanto ella como seu marido, negam todo e qualquer accidente venereo-syphilitico. Estando gravida de 2 para 3 mezes, e sabendo por intermedio de algumas amigas, que na occasião do parto iria soffrer muito, resolveu abortar. Para isso preparou e ingeriu uma forte dose de chá de canella com pinga. Tres quartos de hora depois sentiu fortissimas dôres abdominaes, seguidas de grande hemorrhagia uterina e abortou. Como a hemorrhagia fosse intensa recorreu á Assistencia, que a removeu para a Maternidade.

Preparados da ergotina: Raras são as mulheres chics e cocotes que não conheçam um preparado que contenha essa substancia. Entre elles o mais usado é o Ergo Apiol Schimith. Um nosso amigo, distincto clinico desta capital, nos relatou, além de outros, o caso de uma conhecida que, apezar de seus conselhos, mostrando-lhe os perigos, o emprega com relativa frequencia. Essa mulher, basta notar o atrazo de alguns dias no apparecimento de sua menstruação para tomar algumas pilulas.

Sulfato de strychnina: Por informações de diversos medicos soubemos que esta substancia é tambem empregada com certa frequencia. A observação que reproduzimos não é de abortamento criminoso, mas é o unico caso que possuimos, o que mostra muito bem a acção da strychnina.

Observação N. 7:

M., casada, branca, com 31 annos de edade.

Estando um pouco adoentada procurou seu medico assistente e este, depois de tel-a examinada convenientemente, receitou-lhe 2 granulos por dia de sulfato de strychnina na dose de 0,001 milligramma 
cada um. Momentos depois de ter tomado a segunda dose sentiu-se mal, teve diversas contracções musculares, dôres no ventre e em seguida sobreveiu uma hemorrhagia uterina abortando. $\mathrm{O}$ producto de concepção sahiu em blocco e regula ter mais ou menos quatro mezes e meio. Como a photographia do feto nos foi impossivel por se achar ainda dentro das membranas, pedimos ao collega Doutorando José C. Campos se lhe era possivel tirarmos uma radiographia. A figura ao lado é muito clara mostra muito bem a forma e tamanho da placenta e ainda melhor o esqueleto do feto. (fig. 1).

\section{MEIOS ABORTIVOS MECHANICOS}

Podemos reunir os meios abortivos mechanicos na chave abaixo:

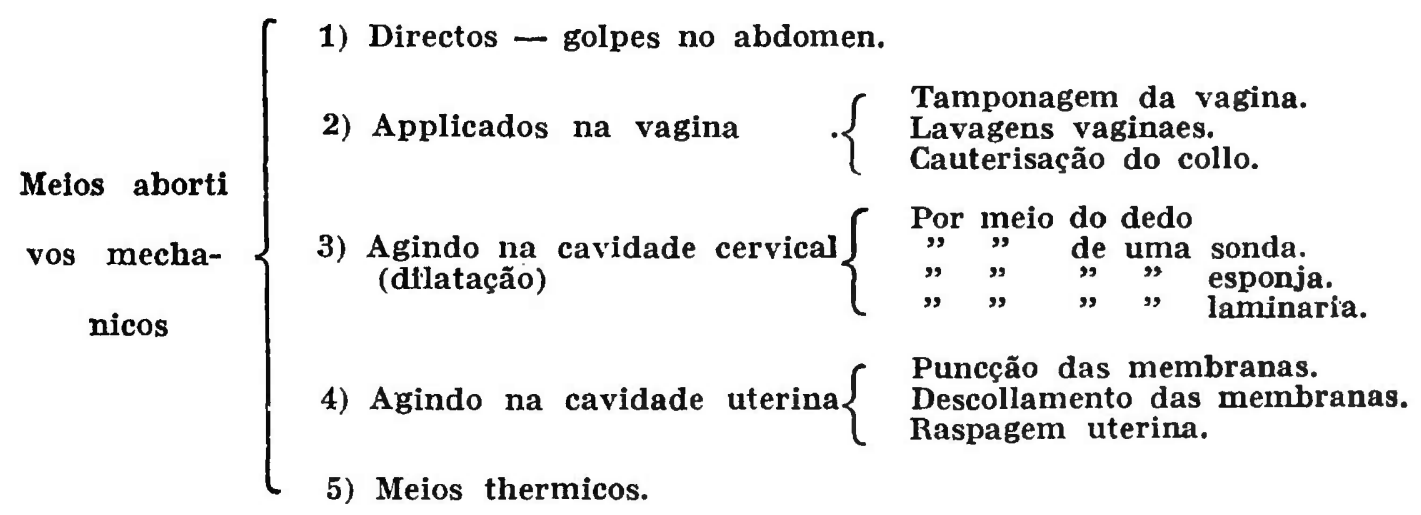

Meios directos: Constituem estas manobras, em golpes exercidos sobre o utero, atravéz da parede abdominal (ponta-pés, choques, etc). São muito raros. De um modo geral pode-se ter uma ameaça de aborto que depois cessa, ou mesmo alguns signaes qu em nada vêm prejudicar a gestação.

Meios applicados na vagina: Dentre as tres variedades que constam na chave acima, os mais communs são: as lavagens vaginaes e cauterisação do collo. Tanto o primeiro como o segundo muito raramente dão o effeito esperado. Como prova citaremos dois casos em que essas manobras apezar de serem praticadas com certa technica e constancia foram sem resultados.

Observação N. ${ }^{\circ} 8$ :

Z. . ., com 20 annos, branca, brasileira, solteira.

Estando gravida de dois mezes e como quizesse esconder, á familia, o fructo de sua leviandade, procurou abortar empregando diversos meios. Praticou diversas vezes por dia e por dias seguidos lavagens vaginaes com agua iodada em temperatura acima de 37 graus, sem conseguir o que desejava. Decidiu então procurar uma parteira, a qual, por meio de uma sonda, a fez abortar. 


\section{Observação N. 9:}

M. C., com 21 annos, branca, solteira, portugueza.

Quando empregada em casa de uma familia foi desvirginada por seu patrão, tornando-se seu amante durante mezes. Como estivesse gravida, procurou uma pessoa entendida no assumpto, afim de que a fizesse abortar. Refere que essa pessoa praticou por diversos dias cauterisações do collo do utero com um medicamento por ella ignorado, mas muito caustico. Apesar do emprego repetido desse methodo não obteve os resultados desejados.

3. - Manobras que agem na cavidade cervical: Entre as parteiras que não têm o minimo escrupulo na pratica do abortamento criminoso, e que fazem desse crime um meio de vida, as manobras preferidas são as de efficacia segura, de execução relativamente facil e que não deixam vestigios. Essas manobras são as seguintes: Dilatação da cavidade cervical por meio do dedo, sonda, laminaria ou esponja, puncção e decollamento das membranas do ovo e raspagem uterina. As tres ultimas são as mais em voga entre nós, sendo que a raspagem uterina é feita por parteiras muito praticas e por certos medicos.

Dilatação da cavidade cervical: E' feita por um dos processos que acabamos de citar. A's vezes são usados instrumentos cirurgicos mais ou menos adaptaveis.

Esta operação por si só não é sufficiente para determinar o abortamento, o qual só se dá quando é attingida a membrana do ovo. Nós a vimos empregar como operação preparatoria para o descollamento, puncção das membranas ou raspagem uterina.

Observação N. ${ }^{0}$ 10:

E. M., com 33 annos, casada, branca, domestica, brasileira.

Refere que ha tres mezes mais ou menos, por soffrer de um corrimento uterino procurou uma parteira, com o fim de se sujeitar ao tratamento que seu mal requeria, e esta, verificando que a paciente além de estar doente estava gravida, aconselhou-a a provocar o abortamento, allegando que o seu estado de saude não permittiria que a gravidez fosse a termo. Fez-lhe diversos toques e o abortamento se deu horas depois.

Tratando-se de uma multipara parece-nos que neste caso tenha havido descollamento das membranas, em vista da grande facilidade com que se deu a passagem do dedo pelo orificio do collo.

Oservação N. ${ }^{\circ} 11$ :

M. C., com 21 annos, branca, solteira, portugueza.

E' o mesmo caso que citamos acima, quando nos referimos á cauterisação do collo do utero. A pessoa que $M$. C. procurou para fazel-a abortar, empregou diversos meios e entre outros fez tambem uso de uma laminaria e de sondas de diversos calibres, e mesmo assim não conseguiu seus intentos. 


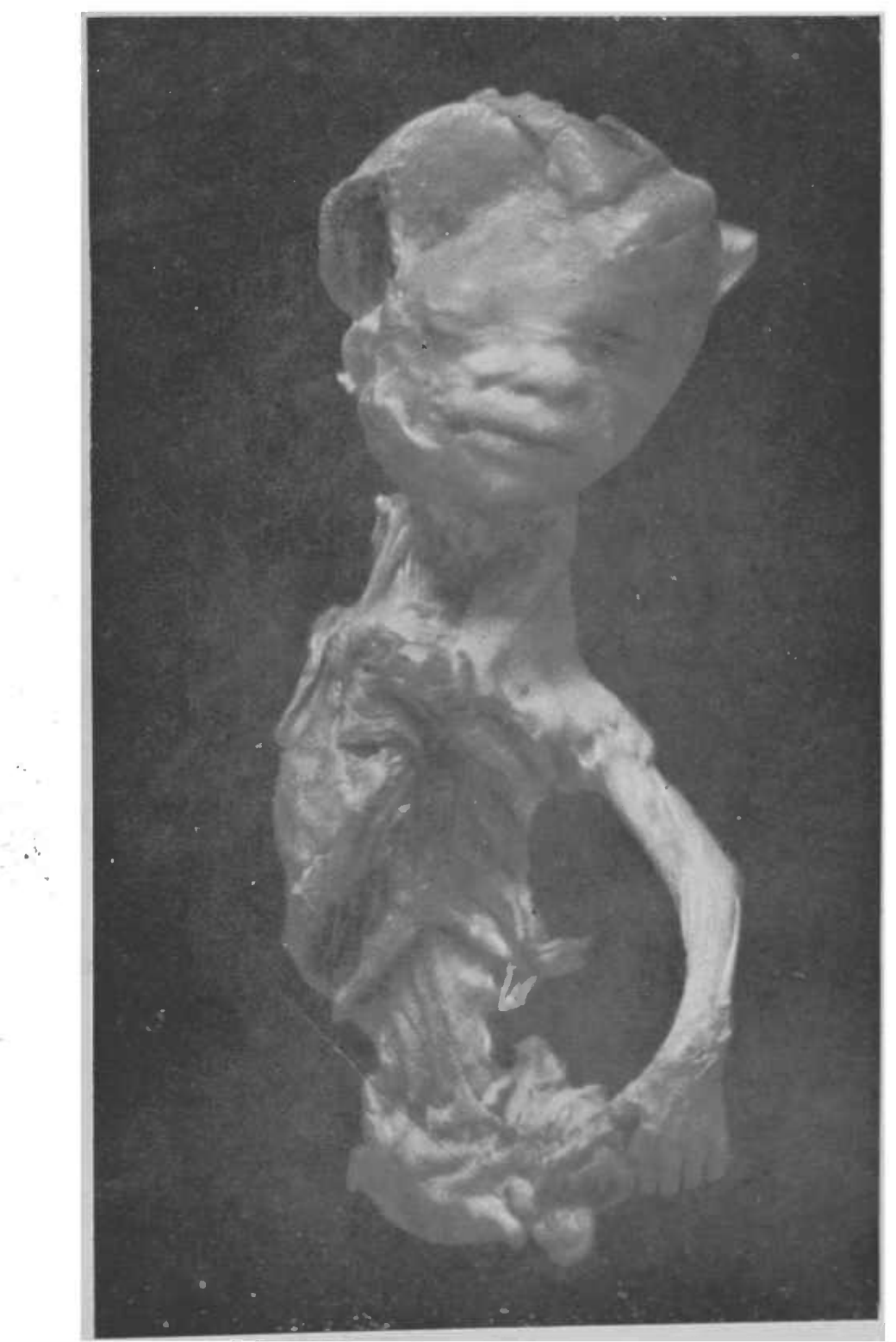

FIG. I 

Meios que agem na cavidade uterina: Temos a puncção ou o descollamento das membranas e a raspagem uterina.

Puncção das membranas do ovo: E' feita com o fim de se determinar a sahida do liquido amnico, de modo que pelo seu parcial esvasiamento o utero se retrae e por conseguinte nelle se provocam contracções uterinas por meio das quaes se effectua o trabalho expulsivo. A sahida do liquido amnico pode ser determinada pela introducção no canal cervical, de pinças, sondas de borracha, fios de arame, espeto de roseira, ou mesmo um dedo, etc.

Grande numero dos abortamentos criminosos entre nós são provocados por esse meio.

Por meio de uma sonda:

Observação N. ${ }^{\circ} 12$ :

Z.. ., com 20 annos, brasileira, solteira, branca.

Estando gravida de dois mezes, e não conseguindo abortar depois de ter feito uso de diversos meios, procurou uma parteira. Esta lhe introduziu uma sonda na cavidade uterina, dando em resultado immediatamente a sahida de certa quantidade do liquido amnico. Dez a doze horas depois abortou.

Por meio de um fio de arame:

Observação N. ${ }^{\circ} 13$ :

M.. ., 27 annos, preta, brasileira, casada.

Por instigação de seu amigo, empregou diversos meios para se fazer abortar. Como não obtivesse resultado, e ouvindo dizer que o melhor meio seria o de se introduzir uma sonda ou qualquer instrumento no utero, quiz tentar. Para isso arranjou um fio de arame e procurou introduzil-o no collo do utero. Dias depois sobreveiu uma metrite agura e abortou. Removida para a Maternidade lá ficou em estado grave durante muitos dias e conseguiu salvar-se.

Espeto de roseira:

Observação N. ${ }^{\circ}$ 14:

Caso relatado pelo Professor Raul Briquet:

X., syria, parteira.

Como estivesse gravida e não quizesse mais ter filhos achou conveniente abortar. Como na occasião, no local onde se achava não conseguisse o material necessario, para isso preparou um galho de roseira, afilou uma de suas pontas e o introduziu no utero, perfurando-o. Disso sobreveiu uma grave peritonite e a morte. Feita a autopsia, encontrou-se no utero uma perfuração na face externa do collo, indo até á cavidade uterina e dahi se continuando na parede do fundo do utero até a cavidade peritoneal.

Descollamento das membranas do ovo: Pode ser feita pelo proprio dedo ou por instrumento introduzido no utero de modo a não perfurar a membrana. Empregam-se injecções intra-uterinas de li- 
quido em discreta pressão ou longas sondas de borracha flexiveis, tendo-se o cuidado de deixar uma parte della para fóra do collo, presa a um tampão de gaze ou algodão.

Injecções intra-uterinas:

Observação N. ${ }^{\circ} 15$ :

Maria D., com 27 annos, casada, brasileira, branca, engommadeira.

Ha 6 mezes está separada de seu marido. No mez de Agosto do corrente anno foi a Santos, onde conheceu um rapaz, com o qual teve relações sexuaes. Nos ultmos dias do mez de Setembro notou que estava gravida. Procurou uma parteira, que depois de ter confirmado esse estado, aconselhou-a para que abortasse, ao que ella consentiu. Para conseguir o abortamento, foi feita uma só lavagem intra-uterina com agua iodada.

Por meio de uma sonda flexivel:

Observação N. ${ }^{\circ}$ 16:

Amelia G., com 23 annos, casada, branca, brasileira.

Refere ter procurado uma parteira, afim de se fazer abortar. Esta lhe applicou por diversas vezes uma sonda flexivel de borracha, durante duas semanas seguidas, retirando-a e applicando-a de 24 em 24 horas. Só depois da terceira semana abortou, mas teve graves complicações para o lado do endometrio, que a obrigaram a guardar o leito por muitos dias.

Por meio de pinças:

Observação N. ${ }^{\circ} 17$ :

Devemos esta observação á extrema gentileza de nosso amigo Dr. Rebello Netto.

B. G., com 16 annos de edade, brasileira, branca, solteira:

Indo á casa de uma parteira afim de se fazer abortar, esta a collocou sobre uma mesa de operações, introduzindo-lhe nos orgãos genitaes uma sonda de borracha. Voltou com essa sonda para casa e 24 horas depois dessa manobra como sentisse dôres insupportaveis no. baixo ventre, voltou á residencia da parteira, a qual collocando-a na mesma mesa da vespera, fez-lhe por meio de pinças uma operação demorada e dolorosa, terminando por extrahir de dentro dos orgãos genitaes o feto que se acha reproduzido na fig. 2. Apresenta-se esse feto muito dilacerado; faltam-lhe, o membro superior direito arrancado ao nivel da articulação escapulo-humeral, os membros inferiores arrancados em totalidade, todo o lado direito do arcabouço costal e todas as visceras thorace-abdominaes. O craneo apresenta uma fenda abrangendo o temporal e parietal direitos, pelo qual sahe a massa encephalica. 


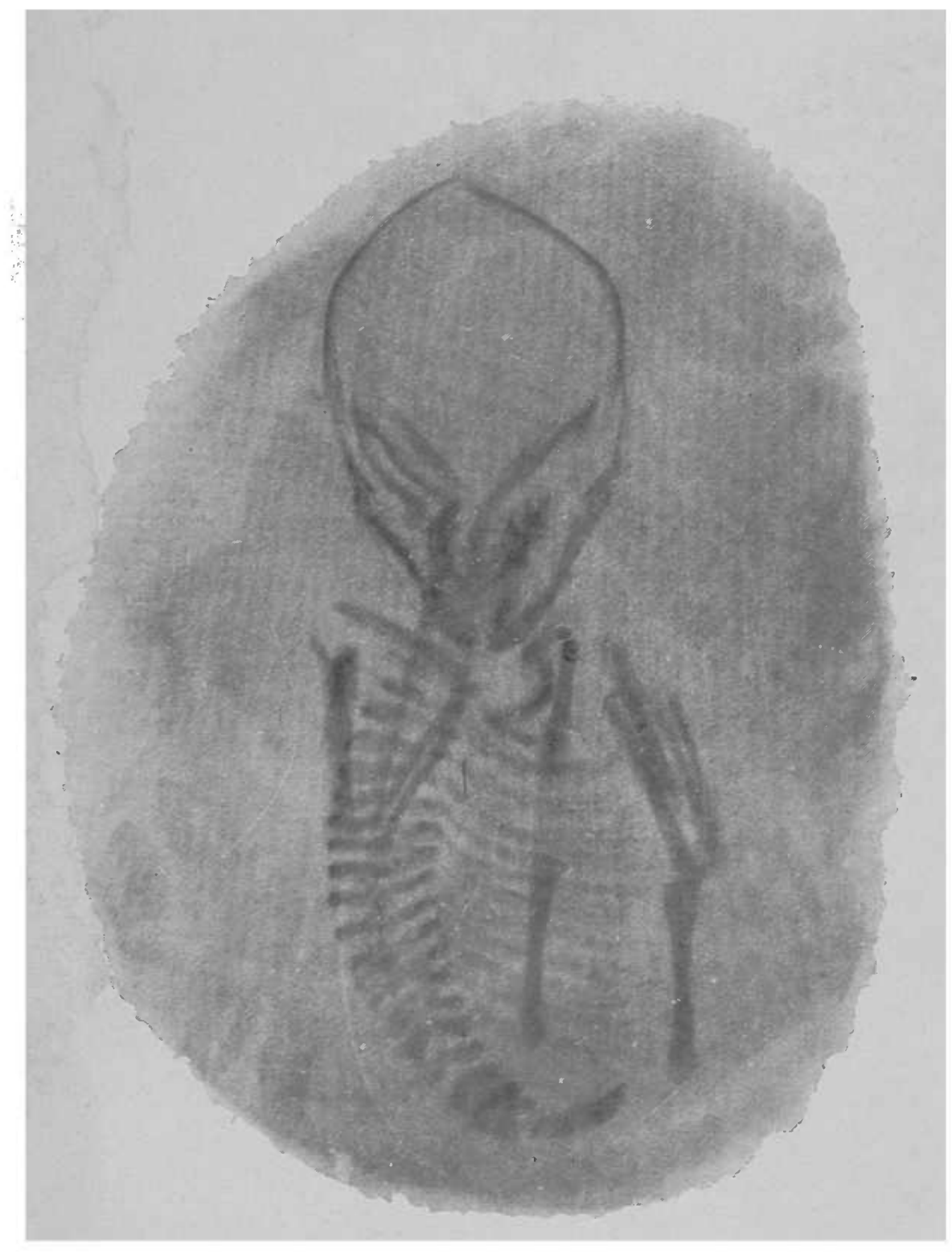

FIG. 2 

Raspagem uterina: E' empregada quando se trata de uma gravidez nos primeiros mezes.

5.0 - Meios thermicos: Antes de recorrer ás especialistas em abortamento, as mulheres gravidas que desejam abortar recorrem a esse meio. São muito usadas as bolsas de gelo, bolsas de agua quente, cataplasmas, etc. sobre o ventre.

\section{MEIOS ABORTIVOS POR MANOBRAS MIXTAS OU MECHANICO-CHIM I CO}

Constam na administração de uma substancia qualquer tida como abortiva, tal como um dos saes de quinino, aguardente, etc., e que as abortadoras ou abortadores lhes attribuem a propriedade de tornar mais permeavel o collo do utero para depois collocarem a sonda de borracha, ou fazer a lavagem intra-uterina. Temos notado uma certa supremacia no emprego deste methodo sobre os outros, é um dos mais usado e rara é a parteira que não faça sua apologia.

LABORATORIO PAULISTA DE BIOLOGIA

\section{SULFOMERCOL}

\section{Sulfureto de mercurio colloidal}

O Sulfómercol é fornecido em caixa de 12 empolas de 1 ou 2 cc. Cada cc. contém grs. 0.01 de sulfureto de mercurio chimicamente puro.

SULFOMERCOL I. - Ampo las de 1 cc. que dererão ser empregadas para os tratamentos anti-syphiliticos communs, $\epsilon$ specialmente nas pessoas fracas e nas mulheres. Nas creanças injectar-se-á somente $1 / 2$ cc.

SULFOMERCOL 1I. - Ampoulas de $2 \mathrm{cc}$. reservadas aos casos graves e nos quaes sa necessita de um tratamento mais energico devedendo-se usal-as somente nos adultos. 